\title{
LAUDATO SI': LA METAFÍSICA DE LA SIGNIFICACIÓN EN EL «CANTICO DI FRATE SOLE»
}

\section{LAUDATO SI': METAPHYSICS OF SIGNIFICANCE IN THE «CANTICO DI FRATE SOLE»}

\section{ÉDISON HIGUERA AGUIRRE ${ }^{1}$}

Recibido: 23 de junio de 2016 Aprobado: 20 de febrero de 2017

\footnotetext{
${ }^{1}$ Pontificia Universidad Católica del Ecuador, Facultad Eclesiástica de Ciencias Filosófico-Teológicas, Escuela de Filosofía, Quito, Ecuador (ehiguera821@puce.edu.ec).
} 



\title{
LAUDATO SI': LA METAFÍSICA DE LA SIGNIFICACIÓN EN EL «CANTICO DI FRATE SOLE»
}

\section{LAUDATO SI': METAPHYSICS OF SIGNIFICANCE IN THE «CANTICO DI FRATE SOLE»}

\author{
Édison Higuera Aguirre
}

Palabras clave: metafísica de la significación, Francisco de Asís, «Cantico di frate Sole», Buenaventura, analogía, simbología

Key words: metaphysics of signification, Francis of Assisi, «Cantico di Frate Sole», Buenaventura, analogy, symbology

\section{RESUMEN}

En el presente artículo se reflexiona sobre la metafísica implícita en el «Cantico di frate Sole» de Francisco de Asís, por medio de la interpretación de Buenaventura de Bagnoregio. El texto se divide en tres partes: en la primera, se establece el significado de las creaturas en el «Cantico»: en él, todas las creaturas reciben su significación última a la luz del Creador; en la segunda, se exponen las doctrinas de la analogía y la simbología de Buenaventura de Bagnoregio: todas las creaturas pueden ser consideradas como sombras, vestigios y/o imágenes del Creador, y como símbolos que remiten a Él; y, en la tercera, se propone la interpretación del texto franciscano, por medio de la analogía y la simbología bonaventurianas: las creaturas que intervienen en el texto son sombras, vestigios y símbolos del «Altissimo» por los diferentes atributos que lo señalan. 


\section{ABSTRACT}

This article ponders the metaphysics implicit in the "Cantico di frate Sole» of Francis of Assissi, thanks to the interpretation of Bonaventure of Bagnoregio. The text is divided into three parts. First, the meaning of the creatures is set into the «Cantico» means: all creatures receives their final significance in the light of the Creator; in the second, the doctrines of analogy and symbolism of Bonaven- ture of Bagnoregio are as follows: all creatures can be considered as shadows, traces and/or images of the Creator, and as symbols that refers to Him; and in the third, the interpretation of the canticle is proposed by analogy and symbolism bonaventurians: creatures involved in the text are shadows, traces and symbols of the «Altissimo» by the different attributes that points to Him.

\section{INTRODUCCIÓN}

El presente artículo, "Laudato si': la metafísica de la significación en el "Cantico di frate Sole»", analiza el significado metafísico de las creaturas en las concepciones de Francisco de Asís y Buenaventura de Bagnoregio. Si la expresión original "Laudato si"' es utilizada por Francisco de Asís para introducir la alabanza del Señor con todas sus creaturas, se propone profundizar su significado. Por ello, se debe preguntar por el sentido profundo de la expresión al interior del texto a la luz de las fuentes franciscanas y de uno de sus principales exégetas: Buenaventura de Bagnoregio.

Su exposición adquiere relevancia y actualidad por dos razones que se implican: 1) Con motivo de la publicación de la Encíclica del papa Francisco
"Laudato si"', en la que el Pontífice propone a Francisco de Asís como modelo "de una ecología integral, vivida con alegría y autenticidad" (papa Francisco, 2015: parágrafo 10); y en la que urge a todos los hombres "a reconducir todas las criaturas a su Creador" (papa Francisco, 2015: parágrafo 83). 2) Por la urgencia del problema ecológico, que exige la integración de sus principales aristas en un horizonte general de comprensión de la relación del hombre, del cosmos y de Dios (papa Francisco, 2015: parágrafo 119).

El autor se propone exponer el significado metafísico de las creaturas en el texto del Cántico de las creaturas de Francisco de Asís, a partir de la interpretación analógica y simbólica de la reali- 
dad realizada por san Buenaventura. Para cumplir con esta finalidad procura: a) establecer el significado de las creaturas al interior del mencionado texto de Francisco de Asís; b) interpretar la analogía y la simbología bonaventurianas, como expresión de la espiritualidad de Francisco de Asís; c) sugerir la interpretación de la obra a partir de la analogía y la simbología bonaventurianas.

Para llevar adelante su cometido, el autor se plantea las siguientes preguntas: ¿Es posible afirmar la existencia de una metafísica de la significación en el cántico franciscano? y ¿Cuál es el «significado» que tienen las creaturas para el hombre colocadas en el horizonte de Dios?

Se debe recordar que el título de la encíclica «Laudato si'», alude al Cántico del hermano Sol, en dialecto umbro, por ello resulta imperioso preguntarse por el sentido original que tienen las creaturas para Francisco de Asís, pues, como bien afirma Martin "la forma en que hablamos acerca de la naturaleza está condicionada por nuestra interpretación de ella" (2015: 171).

Una de las principales contribuciones del presente artículo consiste en el análisis de la expresión «Laudato si'» a partir de su fuente inspiradora y de su ulterior exposición realizada por su discípulo e intérprete Buenaventura de Bagnoregio.
Como hipótesis, se afirma que el análisis filosófico del canto franciscano respalda la tesis del significado metafísico de las creaturas para Francisco de Asís, gracias a la interpretación analógica y simbólica de san Buenaventura.

El artículo se divide en tres partes: en la primera, se expone el significado de las creaturas según el Cántico del Hermano Sol; en la segunda, se explican las doctrinas de la analogía y la simbología bonaventurianas; y en la tercera, se procura la interpretación de la obra a la luz de las fuentes franciscanas y de su discípulo y sucesor en el gobierno de la Orden franciscana Buenaventura de Bagnoregio.

En la primera parte, se recuerda que para Francisco de Asís todas las realidades de este mundo son creaturas, que deben unirse al hombre en la alabanza de su Creador. La segunda parte se construye sobre la premisa de que Buenaventura debe ser considerado el autor que expresa en lenguaje académico la intuición original de su padre Francisco. En ella se recuerda que para el doctor seráfico, las creaturas reflejan la gloria del creador según su constitución propia, como sombras, vestigios o imágenes de Dios; y que la simbología utilizada por Buenaventura, constituye la expresión y aplicación de la triple analogía mencionada. La tercera parte procura interpretar el canto a partir de las conclusiones que 
se extraen, no solo a partir del texto, sino también de la profundización personalísima realizada por Buenaventura.

El autor se sirve de la siguiente metodología: en la primera parte realiza una exégesis de algunas expresiones del canto franciscano; en la segunda, realiza una revisión bibliográfica que da cuenta de diversos estudios especializados sobre la analogía y la simbología en Buenaventura de Bagnoregio. En relación a la bibliografía reportada en esta parte, se debe tomar en cuenta que, no obstante la antigüedad de algunos textos, ellos proceden de una de las más importantes revistas especializadas en estudios bonaventurianos en el mundo (Doctor Seraphicus), lo cual puede constituir una justificación adecuada para su utilización. En la tercera, se aplica una hermenéutica general del texto, en la que se incluyen elementos de análisis bonaventurianos y del papa Francisco.

A continuación se expone el significado metafísico de las creaturas según Francisco de Asís.

\section{EL SIGNIFICADO DE LAS CREATURAS SEGÚN EL «CANTICO DI FRATE SOLE»}

\section{La espiritualidad y la teología durante la época de Francisco de Asís}

La exposición del «Cantico» exige un ejercicio previo de contextualización histórica que permita la comprensión de la espiritualidad y la teología de la segunda parte del siglo XII y principios del siglo XIII.

Francisco de Asís (1181/11821226) y Buenaventura (1217-1274) viven en una "época de movimientos, agitación y cambio, inspirados en la necesidad de adaptarse a la caída del sistema feudal y a las exigencias de una naciente burguesía" (Raitt, 2002: 11). En los campos de la espiritualidad y la teología debe considerarse "un período de transición" (Raitt, 2002: 21), en el que se pasa de una teología espiritual elaborada en los monasterios a una teología elaborada en las universidades.

Surgen en aquella época diversos movimientos interesados en la recuperación de la "simplicidad y la pobreza espirituales" (Raitt, 2002: 25) de la Iglesia. Entre otros, se pueden mencionar: los humiliati, los valdenses (pobres de Lyon), los cátaros, los amaurianos, los arnoldistas, los speronistas, los joaquinitas, etc. (Knowles, 1977: 370-374) Algunos cánones del IV concilio de Letrán (1215) reflejan la intención de la autoridad 
eclesiástica de corregir algunas de las exageraciones y errores que sostenían aquellos grupos. Por ejemplo, el ejercicio de la predicación sin la debida misión eclesiástica. (Denzinger, 1997: 157) Excede el propósito del presente artículo la exposición de la doctrina de los grupos mencionados y de los cánones del mencionado concilio ecuménico.

En su forma exterior, la vida de Francisco de Asís y sus seguidores se asemeja a la de los movimientos poco ortodoxos y hasta heréticos de su tiempo: el interés por la pobreza material y espiritual de la Iglesia, la forma de vida comunitaria, la predicación popular, la simplicidad evangélica, etc. Sin embar- go, su principal diferencia consiste en la obediencia radical prometida por el santo de Asís al Papa y a la Iglesia, en general: "Nace la Orden franciscana como un «movimiento» popular y apostólico, predicando la ortodoxia, la obediencia a los poderes eclesiásticos, y al mismo tiempo predicando la reforma verdadera a todos los cristianos, ricos y pobres, superiores y súbditos" (Flors, 1969: 757).

\section{El significado de las creaturas para Francisco de Asís}

Antes de realizar el análisis de las creaturas para Francisco de Asís, conviene reproducir el texto original del «Cantico», en dialecto umbro:

\section{Cantico di Frate Sole}

Altissimu, onnipotente, bon Signore, Tue so' le laude, la gloria el'honore et onne benedictione.

Ad Te solo, Altissimo, se konfano, et nullu homo ène dignu te mentovare. Laudato sie, mi' Signore, cum tucte le Tue creature, spetialmente messor lo frate Sole, lo qual è iorno, et allumini noi per lui. Et ellu è bellu e radiante cum grande splendore: de Te, Altissimo, porta significatione. Laudato si', mi' Signore, per sora Luna e le stelle: in celu l'ài formate clarite et pretiose et belle.

Laudato si', mi' Signore, per frate Vento et per aere et nubilo et sereno et onne tempo, per lo quale a le Tue creature dài sustentamento.

Laudato si', mi' Signore, per sor'Aqua, la quale è multo utile et humile et pretiosa et casta. 
Laudato si,' mi' Signore, per frate Focu,

per lo quale ennallumini la nocte:

ed ello è bello et iocundo et robustoso et forte.

Laudato si,' mi' Signore, per sora nostra matre Terra,

la quale ne sustenta et governa,

et produce diversi fructi con coloriti flori et herba.

Laudato si', mi' Signore, per quelli ke perdonano per lo tuo amore

et sostengo infirmitate et tribulatione.

Beati quelli ke 'I sosterrano in pace,

ka da te, Altissimo, sirano incoronati.

Laudato si', mi' Signore, per sora nostra Morte corporale,

da la quale nullu homo vivente pò skappare:

guai a.cquelli ke morrano ne le peccata mortali;

beati quelli ke trovarà ne le Tue sanctissime voluntati,

ka la morte secunda no 'l farrà male.

Laudate e benedicete mi' Signore et rengratiate

e serviateli cum grande humilitate. (Francesco d'Assisi, 1997)

El texto fue compuesto por Francisco de Asís, en dialecto umbro, entre 1224 y 1225 , luego de la recepción de los estigmas en el Monte Alvernia. Y puede ser considerado su "testamento" espiritual. (Thompson, 2012: 124) Se resume en la alabanza reiterada de Dios, "Altissimu, omnipotente, bon Signore" (Francesco d'Assisi, 1997: 1), "en unión con todas" o "por medio de todas" (Bizziccari, 1972: 229; Paolazzi, 1992:69) las creaturas.

En ocho ocasiones el autor introduce la alabanza divina con la fórmula "Laudato si', mi' Signore". Con ella hace intervenir a los elementos del mundo en la restitución de aquello que solo a Él "se konfano", esto es "le laude, la gloria e I'honore et onne benedictione".

Cada una de las creaturas convocadas a la alabanza es calificada de hermana/o. De ese modo, Francisco de Asís instituye la fraternidad universal con todas las creaturas del cosmos. Al mismo tiempo, restituye la condición creatural que los elementos de la naturaleza (aire, agua, tierra y fuego) habían perdido, debido a su sacralización. A partir de él, la «sacralidad» de las creaturas procede de su Creador, el cual se encuentra abismalmente separado de ellas: "It can be one in which the created world is sacred and valued for love of its Creator who always 
surpasses it" (Bauckham, 2011: 2009).

El Señor es alabado por "frate Sole", por "sora Luna e le stelle", por "frate Vento", por "sor'Aqua", por "frate Focu", por "nostra matre Terra", por aquellos que perdonan "per lo Tuo amore" y por "nostra Morte corporale". De este modo, el conjunto de la creación, el perdón y nuestra propia muerte corporal parecen asumir un nuevo significado gracias a la mirada contemplativa del hermano Francisco.

El «Cantico» refleja la profundidad espiritual de su autor. Su argumento refleja el desafío constante del alma contemplativa que intenta expresar en palabras sencillas el inefable misterio del Dios Altísimo, en comunión con lo creado.

Pero, ¿qué es lo que canta el «pobrecillo de Asís», que puede ser considerado, al mismo tiempo, tan simple y tan sublime? ¿De dónde brotan aquellas sentidas palabras de la obra franciscana, que son capaces de contagiar a sus oyentes a la alabanza del Creador? ¿Cuál es el nexo entre Francisco de Asís y las creaturas, junto a las cuales se anima a cantar a su Señor? ¿Qué mueve al «santo di Dio» a cantarle "cum tucte le sue (Tue) creature"? ¿Qué es lo que autoriza al autor del artículo a proponer la tesis de la «significación» de las creaturas, si ellas no son lenguaje, en el sentido ordinario de la palabra? ¿Por qué se arriesga el autor del artículo a hablar de una «metafísica» de la significación, si el hermano Francisco no dedicó ninguno de sus escritos a problemas de metafísica? En fin, ¿cuál es el «significado» que tienen las creaturas para el hombre, colocadas en el horizonte de Dios?

El presente trabajo desea responder a la última pregunta planteada, es decir, al problema de la «significación» de las creaturas, contempladas desde la perspectiva de su Creador. Para ello, el autor se sirve del texto de Francisco de Asís y de las contribuciones sobre la analogía y la simbología, propuestas por Buenaventura de Bagnoregio.

De entrada se debe afirmar que Francisco de Asís no es un metafísico de escuela; sin embargo, se puede intuir cierta "perspectiva metafísica" en la obra analizada, porque es capaz de penetrar y expresar con agudeza el carácter profundo de la realidad, contemplada a la luz del Creador.

En este sentido resultan apropiadas las expresiones de Th. Matura (2010: 25), en las que se destaca el descubrimiento de Dios no solo en el cielo, sino también en el mundo visible, especialmente en el ser humano, creado a imagen de Dios: "Once he had discovered God, Francis found that the place of his presence was not only «elsewhere», heaven, but also the visible world, with, at its center, the human person as image of God". 
Por ello, para Francisco, ¿qué son las entidades del mundo natural sino «creaturas» que reflejan la grandeza de su Creador? En su espiritualidad, la naturaleza creatural de las cosas no disminuye en modo alguno su dignidad: "This does not demean the creatures, but gives them their true dignity and worth as precisely creatures of the one Creator" (Bauckham, 2011: 257).

De este modo, pese a no ser un metafísico, en el sentido antes señalado, el santo de Asís es capaz de transmitir a sus seguidores un nuevo modo de interpretar el mundo, desconocido hasta la época. Las creaturas son «hermanas», con un valor que proviene del Dios creador: "By not valuing them as objects of possession, power or gratification for himself, he was freed to treat them all 'fraternally' as fellow-creatures with the value they have for God their Creator" (Bauckham, 2011: 199).

El efecto positivo que Francisco de Asís provocó en sus seguidores se parece al de un río caudaloso, que arrastra los objetos que flotan en su superficie. Lo confirma Matura, con las siguientes palabras:

The medieval thinkers just indicated [Alexander of Hales, Bonaventure of Bagnoregio, Peter John Olivi, Raymund Lull, Roger Bacon, John Duns Scotus, and William of Ockham] were, more or less, influenced by the figure of Francis as presented by the first biographies, and something Franciscan always made its way into their theology and philosophy. (2010: 20)

Por ello, se puede afirmar que el estilo de vida de los hermanos menores, y buena parte de sus escritos, deben ser considerados a la luz de la experiencia inicial de san Francisco. Para Francisco de Asís y sus seguidores, la comprensión de las «creaturas» se encuentra en el extremo opuesto de la «ousía» aristotélica. Por el contrario, todas ellas, a semejanza de «Frate Sole», llevan inscritas en su interior la «significatione» de su Señor. Esto quiere decir que las creaturas, pese a no ser «lenguaje», en el sentido habitual de la palabra, debido a su belleza están cargadas de la significación de su Señor. De ese modo, "L'autore viene ad inserirsi, inconsapevolmente, nell'antica tradizione della metafisica della luce per cui la bellezza è, nella suggestiva definizione del Ficino, splendor divini vultus" (Bizziccari, 1972: 239-240).

Si bien, de acuerdo a Bizzicari, la belleza de las creaturas permite descubrir un nexo con una antigua tradición metafísica, se requiere el análisis de su contenido desde la obra de sus discípulos.

Las reflexiones que se desarrollan a continuación parten de la convicción 
de que el pensamiento de san Buenaventura representa la formulación académica de las intuiciones espirituales de Francisco de Asís, pues, para aquel, este representa "el modelo humano a seguir para llegar a Dios" (Lázaro, 2008: 111), y hasta "el verdadero valor de la santidad" (Malaguti, 1996: 90). Porque, como afirma Cilento, si Francisco de Asís debe ser considerado "el caballero de la Dama Pobreza y el poeta del hermano Sol [...] san Buenaventura es el legislador más circunspecto de esta milicia y el exégeta de aquel Cántico" (1966: 62).

Una confirmación adicional del «efecto Francisco» sobre Buenaventura se puede descubrir en el corazón del pensamiento bonaventuriano, esto es en el ejemplarismo, según lo afirma J. Bougerol. Según este, el ejemplarismo bonaventuriano se inspira en la doctrina de Francisco de Asís (Bougerol, 1983: 13). Otro tanto se debe afirmar sobre las doctrinas de la analogía y la simbología bonaventurianas, como se explica más adelante.

Una vez que se ha realizado la exposición del significado «metafísico» de las creaturas para Francisco de Asís, se presentan las doctrinas de la analogía y la simbología en el pensamiento de Buenaventura de Bagnoregio.

\section{LA ANALOGÍA Y LA SIMBOLOGÍA EN SAN BUENAVENTURA}

\section{El problema del aristotelismo en la Universidad de París y el aristotelismo de Buenaventura}

Antes de la exposición de las doctrinas de la analogía y la simbología bonaventurianas, se presentan algunos datos históricos sobre el problema de la incorporación de las obras de Aristóteles en la Universidad de París y sobre el "aristotelismo" de Buenaventura que podrían ayudar a comprender su posición filosófica.

Hacia 1120 se inicia en Toledo (España) un importante movimiento de traducción de obras filosóficas y científicas, entre ellas las obras de Aristóteles. (Steenberghen, 1955: 28; Chenu, 1992: 309; Brams, 2003: 25) La traducción de las obras de Aristóteles y de otros filósofos griegos se multiplica durante la segunda mitad del siglo XII. (Stabile, 1995: 726) En 1255 la Facultad de Artes establece un nuevo pensum, en el que se introduce el estudio oficial de los libros aristotélicos conocidos. (Steenberghen, 1955: 35; Verger, 1996: 70; Damiata, 2004: 9) El redescubrimiento de Aristóteles marca 
profundamente el pensum de la Universidad de París, de modo que hacia la mitad del siglo XIII, "toutes les facultés des arts sont devenues, en fait, des facultés de philosophie, où l'on enseigne la philosophie d'Aristote" (Steenberghen, 1974: 489). Por ello, resulta innegable que para aquella época, la Facultad de Artes de París se había convertido en la principal fragua de aristotelismo latino. (Steenberghen, 1955: 40)

La incorporación del aristotelismo en París, a mediados del siglo XIII, produjo una lucha encarnizada entre los maestros del clero diocesano y los maestros de las órdenes mendicantes (predicadores y mendicantes). (Congar, 1961: 35) Los primeros son vistos como la línea «progresista» y los segundos como la línea «tradicional». (Steenberghen, 1955: 36) Se puede decir que la disputa se realiza entre una noción de sabiduría cristiana, de origen agustiniano, y otra llamada «natural», desarrollada por la incorporación de las obras naturales de Aristóteles. (Gregory, 1964: 6; Mauro, 1982: 9)

Existen diversas interpretaciones sobre la posición académica de Buenaventura en relación a Aristóteles. A continuación se enumeran y se exponen, brevemente, las hipótesis que, a juicio del autor, resultan más significativas para la comprensión del aristotelismo bonaventuriano: a) el agustinismo antiaristotélico, de Gilson; b) el aristotelismo agustinizan- te, de Steenberghen; c) el antiaristotelismo profético escatológico, de Ratzinger; $y, d)$ el agustinismo aristotelizante, de Maranesi.

a) El agustinismo antiaristotélico: según Etienne Gilson, Buenaventura "conoce bastante bien a Aristóteles, lo cita constantemente, toma prestado de él gran parte de su vocabulario técnico, lo admira sinceramente (...) pero no lo estima" (Gilson, 1995: 11).

b) El aristotelismo agustinizante: según Fernand van Steenberghen, "The philosophy of St Bonaventure is an eclectic and Neoplatonic Aristotelianism, subordinated to an Augustinian theology. In philosophy Augustinianism is one of the sources of his thought, but is a secondary source compared with Aristotelianism". (Steenberghen, 1955: 61).

c) El antiaristotelismo profético escatológico: según Joseph Ratzinger, en la obra de Buenaventura se pueden detectar tres formas de antiaristotelismo, diversos en cuanto al objeto y la intensidad: el antiaristotelismo metafísico, el antifilosofismo (contra los aristotélicos de su tiempo), y el antiaristotelismo profético-escatológico, presente en las Collationes in Hexaëmeron: "En el Hexaëmeron se produce una última agudización del antifilosofismo que se vuelve antiescolasticismo profético, en el que confluyen motivos franciscanos, joaquinitas y dionisianos" (Ratzinger, 2010: 232). 
d) El agustinismo aristotelizante: Para Pietro Maranesi la comprensión filosófica, marcadamente aristotélica, representa uno de los momentos del único y progresivo retorno del hombre a Dios, de tipo agustiniano. Así, buena parte de las herramientas utilizadas por Buenaventura son de origen aristotélico, pero la estructura de fondo es agustiniana. (Maranesi, 1995: 300)

Las diversas tesis interpretativas sobre el aristotelismo bonaventuriano constituyen el ejemplo que se trata de un problema aún abierto y debatido entre los especialistas de la historia de la filosofía del siglo XIII. En el presente artículo no se han expuesto todas aquellas para conservar la investigación dentro de los límites propuestos.

Luego de la anunciada contextualización histórica, se explica en qué consisten la analogía y la simbología bonaventurianas.

\section{La doctrina analógica de Buenaventura}

El horizonte de comprensión de la analogía bonaventuriana es el ejemplarismo metafísico. Según el ejemplarismo, de origen agustiniano, Dios:

(...) es la fuente de toda la realidad, pues es el Logos la realidad plena. El ejemplarismo es un camino metafísi- camente descendente: de Dios a las cosas del mundo que encuentran en Dios su molde y realidad. Un descenso también epistemológico, pues si bien el hombre es el sujeto del conocimiento, este deviene el «plus» que supone la iluminación en la capacidad abstractiva por parte de Dios. (...) Los seres creados son huellas, indicadores (vestigios) de Dios que no contienen el ser que significan, como se puede ver en De doctrina christiana. Solo epistemológicamente la relación es posible, siempre debido a la gracia divina. (Lázaro, 2008: 121)

Buenaventura se apropia del ejemplarismo agustiniano y lo modifica en su parte estructural. Pues, aunque el camino parte de Dios (vía descendente), concede importancia a la vía ascendente, que va del hombre a Dios, "pues es la creatura la que ha de ir descubriendo su relación expresiva con Dios" (Lázaro, 2008: 122). En el marco de aquella vía ascendente se debe destacar la importancia de la doctrina de la analogía bonaventuriana.

En términos generales, se entiende por analogía "la correlación entre los términos de dos o varios sistemas u órdenes" (Ferrater Mora, 1981:147). Cuando Buenaventura aplica la analogía a Dios y a las creaturas, reconoce que entre ellos 
existe diversidad y similitud. Son diversos porque Dios es infinito y las creaturas limitadas; son semejantes porque "la causa deja siempre su huella sobre aquello que ella produce" (Beschin, 2000: 45).

Los diversos grados de proximidad y de separación por los que las creaturas reflejan a su Creador, propuestos por Buenaventura, pueden considerarse la expresión académica de la contemplación espiritual del mundo material operada por Francisco de Asís. Cuando Buenaventura examina las creaturas según el canon de la analogía, descubre que todas ellas son expresión de la bondad y la belleza de su Señor. Por ello, antes que detenerse en la pura negatividad de las creaturas, esto es en lo que las separa de Dios, la analogía del doctor seráfico destaca su positividad como sombras, vestigios o imágenes de Dios, es decir, destaca su expresividad divina.

\section{Las creaturas como sombras (umbrae), vestigios (vestigii) o imagen (imago) de Dios en la doctrina analógica de san Buenaventura}

La analogía bonaventuriana distingue diversos grados por los que las creaturas representan a su Creador. Son tres los grados escogidos por Buenaventura para reflejar la proximidad o la distancia que las separa del Creador; y la claridad o la confusión en la forma de representarlo. Las creaturas pueden ser sombras, vestigios o imágenes del Creador.

Bonaventure divides creatures according to their degree of representing God and classifies them in a descending scale: similitude, image, vestige, and shadow. Shadow refers to a general reflection of God; vestige indicates the reflection of God's power, wisdom, and goodness; image refers to rational creatures and indicates the presence of God reflected within subjectivity in the memory, understanding and will; similitude refers to the rational creature transformed by grace. (Cousins, 1978: 169)

Las sombras son representaciones distantes y confusas de Dios; los vestigios son representaciones distantes y distintas del Creador; y las imágenes son representaciones distintas y cercanas del Señor. Se debe aclarar, sin embargo, que ninguno de los grados enumerados pretende destacar la «negatividad» de lo creado, sino, únicamente, su mayor o menor capacidad representativa de Dios. (Gilson, 1965: 191-192)

Adicionalmente, se debe recordar que para Buenaventura las creaturas pueden ser consideradas sombras de Dios debido a las propiedades que lo vinculan a Él, cuando no establecen el tipo de causalidad bajo el cual son analizadas. Mien- 
tras que las creaturas son vestigios de Dios cuando definen el tipo de relación causal con Dios, en cuanto causa eficiente, ejemplar o final. Finalmente, las creaturas son imagen de Dios cuando este es reconocido no solo como causa sino como objeto. (Gilson, 1965: 191-192)
El esquema que se reproduce a continuación permite visualizar el alcance de la analogía bonaventuriana. En él se destacan el modo de representación, las propiedades que se toman en consideración, el conocimiento al que ellas conducen y las creaturas que poseen dichas cualidades:

Tabla 1: Sombras, vestigios e imágenes en la doctrina de la analogía de Buenaventura

\begin{tabular}{|l|l|l|l|l|}
\hline & $\begin{array}{l}\text { Modo de represen- } \\
\text { tación }\end{array}$ & $\begin{array}{l}\text { Propiedades consi- } \\
\text { deradas }\end{array}$ & $\begin{array}{l}\text { Conocimiento al que ellas } \\
\text { conducen }\end{array}$ & $\begin{array}{l}\text { Seres que las } \\
\text { poseen }\end{array}$ \\
\hline Sombras & Distante y confusa & $\begin{array}{l}\text { Aquellas que tienen a } \\
\text { Dios como causa }\end{array}$ & $\begin{array}{l}\text { Atributos comunes a las Tres } \\
\text { Divinas personas }\end{array}$ & $\begin{array}{l}\text { Materiales y } \\
\text { espirituales }\end{array}$ \\
\hline Vestigios & Distante y distinta & $\begin{array}{l}\text { Aquellas que tienen a } \\
\text { Dios como representa- } \\
\text { ción según alguno de } \\
\text { los tipos de causalidad }\end{array}$ & $\begin{array}{l}\text { Atributos apropiados a Una } \\
\text { Persona }\end{array}$ & $\begin{array}{l}\text { Materiales y } \\
\text { espirituales }\end{array}$ \\
\hline Imagen & Cercana y distinta & $\begin{array}{l}\text { Aquellas que tienen a } \\
\text { Dios como objeto }\end{array}$ & $\begin{array}{l}\text { Atributos que son propios a una } \\
\text { sola Persona }\end{array}$ & $\begin{array}{l}\text { Solamente } \\
\text { espirituales }\end{array}$ \\
\hline
\end{tabular}

(Gilson, 1965: 467)

La siguiente cita del Itinerarium permite confirmar, no solamente los elementos propios del pensamiento de Buenaventura, por el cual las creaturas tienen el carácter de vestigios o imágenes del Creador, y sirven de escalera para subir hasta él, considerado como primer Principio; sino también el nexo indiscutible con su Padre Francisco, para quien las creaturas conservan la huella de su hacedor:
Porque, según el estado de nuestra naturaleza, como todo el conjunto de las criaturas sea escala para subir a Dios, y entre las criaturas unas sean vestigio, otras imagen, unas corporales otras espirituales, unas temporales, otras eviternas, y, por lo mismo, unas que están fuera de nosotros y otras que se hallan dentro de nosotros, para llegar a considerar el primer Principio, que es espiritualísimo y eterno y supe- 
rior a nosotros, es necesario pasar por el vestigio, que es corporal y temporal y exterior a nosotros, -y esto es ser conducido por la senda de Dios-, es necesario entrar en nuestra alma, que es imagen eviterna de Dios, espiritual e interior a nosotros -y esto es entrar en la verdad de Dios-; es necesario, por fin, trascender al eterno espiritualísimo y superior a nosotros, mirando al primer Principio, y esto es alegrarse en el conocimiento de Dios y en la reverencia de la majestad. (Buenaventura de Bagnoregio, s/f: cap. I,2)

Al proponer una «metafísica de la significación» en el Cántico del Hermano Sol, no se quieren exagerar las virtualidades de su contenido. Simplemente se afirma que para san Francisco, como para san Buenaventura, las creaturas dejan de ser simples entes en el mundo, para transformarse en lenguaje del Creador (papa Francisco, 2015: parágrafo 84). En este sentido, el mundo es "como un libro" (Chavero, 1990: 6; papa Francisco, 2015: parágrafo 12) o un "inmenso sacramento" (Bougerol, 1983: 13) en el que se pueden detectar sus palabras o sus signos, donde todas y cada una de las creaturas son expresión de la bondad originaria de Dios: "Cada creatura llega a ser plenamente sí misma, alabando al Señor y manifestando su gloria" (Beschin, 2000: 44).

Adicionalmente, se debe recordar que para Buenaventura las creaturas poseen una estructura trinitaria, reflejo de la «estructura» de Dios. De ese modo, la analogía bonaventuriana, conduce a una solución contemplativa de la creación, en la cual el «homo viator» puede descubrir al Dios trinitario:

El santo franciscano [san Buenaventura] nos enseña que toda criatura lleva en sí una estructura propiamente trinitaria, tan real que podría ser espontáneamente contemplada si la mirada del ser humano no fuera limitada, oscura y frágil. (papa Francisco, 2015: parágrafo 239)

En resumen, a la luz de la doctrina de la analogía, todas las creaturas pueden ser contempladas como expresión o reflejo del Creador. Sin embargo, se debe dar un paso más para comprender la razón por la cual Buenaventura, como buena parte de los autores medievales, se vale del lenguaje simbólico para exponer su doctrina.

\section{La simbología bonaventuriana, como expresión y aplicación de la analogía}

La simbología constituye un recurso de la espiritualidad medieval que permite a los autores destacar la relación de las cosas con el Dios eterno. (Cilento, 1966: 67) Se caracteriza por el uso 
de un código lingüístico comúnmente aceptado. Tan extendido es su uso, que constituye "el organon del pensamiento medieval" (Cilento, 1966: 67).

De ese modo se comprende la razón por la que algunos textos de Buenaventura, como el Itinerarium mentis in Deum y el Lignum vitae-por mencionar dos ejemplos- se encuentran saturados de elementos simbólicos. En ellos, todas las creaturas, hasta aquellas aparentemente insignificantes, se transforman en signos que dirigen la mente del creyente a Dios (Beschin, 2000: 48), pues "las cosas son para él [para Buenaventura], como para San Francisco, otros tantos signos que remiten a Dios" (Berti, 1985: 21; papa Francisco, 2015: Oración cristiana con la creación).

Por ello, la analogía bonaventuriana puede ser considerada "como un código de interpretación para una lectura simbólica, alegórica, no literal de la realidad" (Berti, 1985: 21). Según Cilento, la analogía debe ser considerada la ley general de la creación; mientras que el simbolismo representa el modo en el que dicha ley se expresa y aplica (Cilento, 1966: 74; Todisco, 1980: 6).

Pero, ¿cuál es la importancia del lenguaje simbólico en el marco del pensamiento de Buenaventura? ¿Es posible afirmar que la analogía y la simbología son elementos inseparables del pensamiento de Buenaventura?
Para responder estas preguntas, se debe reconocer, de entrada, que el lenguaje simbólico de Buenaventura representa un modo constitutivo de la expresión de su pensamiento. Simbología y analogía son inseparables, pues, los símbolos pretenden articular en imágenes alusivas la ley general de la analogía de las creaturas. Parece indispensable recordar, además, que el lenguaje simbólico no constituye para el doctor seráfico un simple recurso literario, sino más bien su modo personal de exponer su doctrina filosófico-teológica (Cousins, 1978: 161), pues Buenaventura pertenece a aquella larga tradición de autores medievales que se sirve del lenguaje simbólico para exponer su propia visión teológica (Cousins, 1978: 165).

En el símbolo Buenaventura logra unificar los términos opuestos; en él se realiza la unión de lo finito y lo infinito, de lo máximo y lo mínimo y se puede descubrir la manifestación de lo divino en la realidad material (Cousins, 1978: 161).

Entre los principales símbolos presentes en el Itinerarium mentis in Deum se pueden mencionar: el itinerario, el espejo, el monte, el tabernáculo, la luz, las tinieblas, el serafín con las seis alas y el querubín (Buenaventura, s/f; Cousins, 1978: 165-166). En la misma obra, es posible encontrar otros tantos elementos simbólicos de profundas resonancias espirituales para el hombre medieval: el 
alma, la puerta, el templo, el serafín, el querubín, el día, el tabernáculo, el arca, la luz, los números, el propiciatorio, el trono, etc. (Buenaventura, s/f). En el presente artículo, se omite el análisis de los símbolos mencionados por razones de espacio. Sin embargo, se expone a modo de ejemplo la simbología del «itinerario». El término aparece en una de sus obras más conocidas Itinerarium mentis in Deum. El término neutro itinerarium se refiere a la descripción de un viaje. Iter, itineris, en sentido propio "dicitur de brevi ambulatione"; mientras que, en sentido amplio, significa "via, ratio, institutum" (Forcellini; 1949: 945-947). En el caso que nos ocupa, se trata de la descripción del viaje del alma a Dios; de los pasos que esta debe dar y de las ayudas que recibe de las creaturas, en cuanto sombras, vestigios o imágenes de Dios, para su ascenso a Dios.

En síntesis, la doctrina de la analogía bonaventuriana destaca el valor de las creaturas como sombras, huellas o imágenes de Dios. Esta ley general de la creación se expresa bellamente a través de una rica simbología, en la que cada uno de los símbolos destaca la relación entre el símbolo y el Creador.

A continuación se realiza la interpretación del texto franciscano por medio de la propuesta analógica y simbólica de Buenaventura.

\section{EL «CANTICO DI FRATE SOLE» INTERPRETADO A LA LUZ DEL PENSAMIENTO BONAVENTURIANO}

Como se ha señalado anteriormente, Buenaventura puede ser considerado el exégeta del Cántico de las creaturas (Cilento, 1966: 62). Por ello, parece lícito interpretar su texto a la luz de la propuesta bonaventuriana. Pero, ¿qué añade el exégeta (Buenaventura), que el poeta (Francisco) no haya logrado expresar con claridad?

Para responder a la pregunta planteada, primero se recuerda el modo en que Buenaventura, en la «Leyenda Mayor», describe la relación de Francisco de Asís con las creaturas:

Impulsado por el afecto de su extraordinaria devoción, degustaba la bondad originaria de Dios en cada una de las criaturas, como en otros tantos arroyos derivados de la misma bondad; $y$, como si percibiera un concierto celestial en la armonía de las facultades y movimientos que Dios les ha otorgado, las invitaba dulcemente -cual otro profeta David- a cantar las alabanzas divinas 
(Sal 148,1-14). (Fuentes Biográficas Franciscanas, s/f: LM 9,1)

Con la frase "degustaba la bondad originaria de Dios en cada una de las criaturas", se resume el sentido originario que Francisco de Asís asignaba a las creaturas, según la interpretación de Buenaventura. Francisco percibe y saborea la bondad originaria del Creador en cada una de sus obras. Es capaz de descubrir la bondad originaria de las creaturas, como un eco de la obra de la Creación. De modo que cada una de ellas es capaz de evocar la bondad originaria de su hacedor.

Además, la expresión "las invitaba dulcemente -cual otro profeta David- a cantar las alabanzas divinas", parece aludir al texto franciscano en la que Francisco de Asís invita a las creaturas a la alabanza del «Signore». Según Buenaventura la invitación de Francisco se caracteriza por la dulzura, pues el juglar de Dios no exige a las creaturas el reconocimiento del Creador, sino que las invita dulcemente. Aquella invitación implica, además, que las creaturas se transforman en interlocutores válidos de Francisco, reconociéndoles dignidad o valor. Y el "concierto celestial" de las facultades y movimientos de las creaturas, que, según Buenaventura intuye en ellas Francisco de Asís, señala con insistencia a la fuente que se las "ha otorgado".
Más allá de la nota biográfica de la «Leyenda Mayor», en la que Buenaventura produce una imagen de la relación armoniosa entre Francisco y las creaturas, se pueden señalar otros textos en los que Buenaventura asimila formalmente las enseñanzas de su padre Francisco de Asís.

Por ejemplo, en el Itinerarium mentis in Deum, Buenaventura afirma: "Relucet autem Creatoris summa potentia et sapientia et benevolentia in rebus creatis" (Buenaventura, 1882-1902: 298). En este caso, es evidente que Buenaventura no se detiene en la exégesis de un texto de Francisco, sino que propone sus propias ideas. Según la cita del Itinerarium, en las creaturas («in rebus creatis») se puede descubrir el resplandor del Creador. Esto quiere decir que, a ejemplo de Francisco de Asís, para Buenaventura todas las creaturas son reflejo de la gloria de Dios. Ellas proclaman que el Creador es poderoso, sabio y benevolente en grado máximo (summum). De ese modo, se transforman en lenguaje que remite a Dios.

En el «Cantico» Francisco de Asís parece recuperar la visión originaria que Dios tiene del mundo en el momento mismo de la Creación: "Vio Dios cuanto había hecho, y todo estaba muy bien" (Gn 1,31a). Por ello, se podría afirmar que para el santo de Asís, el mal no forma parte de la estructura ontológica de los entes, pues todos fueron hechos 
buenos por Dios. Ni siquiera el lobo de Gubbio es «malo», sino que es llamado "hermano" (Directorio Franciscano, s/f: párr. 3), pues "la bondad de la creatura nace de la bondad de Dios creador" (Lázaro, 2008: 135).

De hecho, la lectura detenida del Cántico de las creaturas permite comprender que cada una de las creaturas que son invitadas por el poeta de Dios, lo hacen en virtud de los atributos de bondad que el mismo Creador ha inscrito en ellas. Ellas alcanzan el nivel de significación/lenguaje cuando transmiten al mundo la gloria que el «bon Signore» ha inscrito en ellas.
Las creaturas (el sol, la luna, las estrellas, el fuego, etc.) reflejan la gloria de su Señor cuando cumplen la finalidad para la que Él mismo las ha creado: por ejemplo, el sol "por el cual nos alumbras"; el fuego, "por el cual alumbras la noche", la madre tierra, "la cual nos sustenta y gobierna, y produce diversos frutos con coloridas flores y hierba", etc. Y, a través de dichas acciones, reflejo de su Señor (propia de cada una), ellas demuestran su «significación» originaria.

Si se introducen los elementos del Cántico del Hermano Sol en el esquema analógico de Buenaventura se obtiene el siguiente resultado: 
Tabla 2: El «Cantico di frate Sole» desde la analogía bonaventuriana

\begin{tabular}{|c|c|c|c|}
\hline $\begin{array}{l}\text { Formas de representación } \\
\text { de las creaturas, según } \\
\text { Buenaventura }\end{array}$ & $\begin{array}{l}\text { Sombras } \\
\text { La representación del Creador } \\
\text { es distante y confusa. } \\
\text { De modo general, remiten a } \\
\text { Dios como causa, sin especi- } \\
\text { ficar el tipo. } \\
\text { Señalan atributos comunes a } \\
\text { las Tres divinas Personas } \\
\text { Se predica de creaturas } \\
\text { materiales y espirituales }\end{array}$ & $\begin{array}{l}\text { Vestigios } \\
\text { La representación del Creador } \\
\text { es distante y distinta. } \\
\text { Tienen a Dios como represen- } \\
\text { tación según la causalidad } \\
\text { ejemplar, eficiente y final. } \\
\text { Conducen a uno de los } \\
\text { atributos apropiados a Una } \\
\text { de las Tres divinas Personas. } \\
\text { Se predica de creaturas } \\
\text { materiales y espirituales. }\end{array}$ & $\begin{array}{l}\text { Imagen } \\
\text { Generan una representación } \\
\text { cercana y distinta del Creador. } \\
\text { Las propiedades consideradas } \\
\text { tienen a Dios como objeto. } \\
\text { Conducen a atributos que son } \\
\text { propios de una sola persona } \\
\text { de la Trinidad. } \\
\text { Se predica únicamente de } \\
\text { creaturas espirituales. }\end{array}$ \\
\hline \multicolumn{4}{|l|}{$\begin{array}{l}\text { Creaturas mencionadas en } \\
\text { el «Cantico di frate Sole» de } \\
\text { Francisco de Asís }\end{array}$} \\
\hline 1) El hermano Sol & Sí & Sí & No \\
\hline $\begin{array}{l}\text { 2) La hermana luna } \\
\text { 3) y las estrellas }\end{array}$ & Sí & Sí & No \\
\hline $\begin{array}{l}\text { 4) El hermano Viento, } \\
\text { el aire y el nublado y el sereno } \\
\text { y todo tiempo }\end{array}$ & Sí & Sí & No \\
\hline 5) La hermana Agua & Sí & Sí & No \\
\hline 6) El hermano Fuego & Sí & Sí & No \\
\hline 7) La madre Tierra & Sí & Sí & No \\
\hline
\end{tabular}

\section{Elaborado por Édison Higuera Aguirre}

Según el cuadro que antecede, para Francisco de Asís el Sol, la Luna, las Estrellas, el Viento, el Agua y el Fuego, además de ser creaturas son «hermanos/ as»; y la Tierra es «madre». Son nuestros hermanos/as. De ese modo, aunque no se niegue la diferencia que existe entre el hombre y las demás creaturas, Francisco de Asís inaugura una forma de fraternidad universal, por la que los seres humanos deben sentirse cercanos a las demás obras de la creación.

Según la analogía bonaventuriana, las creaturas mencionadas en el texto 
pueden ser consideradas sombras y vestigios de Dios. Ninguna de ellas alcanza el grado de imagen. El Sol, la Luna, las Estrellas, el Viento, el Agua, el Fuego y la Tierra pueden ser consideradas sombras y vestigios porque representan de modo distante y distinto a Dios; porque lo señalan como su causa ejemplar, eficiente y final; y porque dirigen nuestra mente a la consideración de uno de los atributos apropiados, a una de las Tres divinas personas, por ejemplo a la consideración de su poder, su bondad o su sabiduría.

Para Francisco de Asís la significación de las creaturas se revela a la luz de Dios. Cada una de ellas expresa de un modo particular a su Hacedor, spetialmente messor lo frate Sole. (Francesco d'Assisi, 1997: párr. 3) Para Buenaventura, los esplendores de las cosas creadas (rerum creaturarum splendoribus) y sus tantos clamores (tantis clamoribus) conducen al hombre a ver, oír, alabar, amar y reverenciar, ensalzar y honrar a Dios in omnibus creaturis. (Buenaventura, 1882-1902: I,15) Por ello, para ambos autores la única significación posible de las creaturas se descubre a partir del acto creador. Su metafísica es aquella que les asigna el significado que tienen a la luz de la creación. En el caso de Francisco, como hermanos/hermanas; en el caso de Buenaventura, como sombras y vestigios.

Detrás del insistente llamado del papa Francisco a cuidar "nuestra casa común" (2015: parágrafos 1, 3, 13, 17, etc.) se percibe una espiritualidad que no solo invita a "pasar de lo exterior a lo interior para descubrir la acción de Dios en el alma, sino también llegar a encontrarlo en todas las cosas" (papa Francisco, 2015: parágrafo 233). Probablemente, la inspiración de aquella contundente afirmación provenga no solo del texto que se ha analizado en el presente artículo, sino también de la doctrina del doctor seráfico, Buenaventura de Bagnoregio.

En síntesis, una relectura del texto franciscano, a la luz del pensamiento bonaventuriano, debe integrar su doble concepción analógica y simbólica de las creaturas. Por medio de ellas se revela que las creaturas tienen la virtud expresiva de ser o sombras, o vestigios, o imágenes del Creador; y que la imagen de algunas de las creaturas puede servir de símbolos que remiten a su Hacedor. Esto quiere decir que para Buenaventura la «significatione» que Francisco atribuye al «messor lo frate Sole», se traduce en términos de sombras o vestigios del Creador; y, más profundamente, en un símbolo que remite a la luz de Dios. 


\section{CONCLUSIONES}

Según el autor del «Cantico» todos los elementos del cosmos son creaturas y hermanos. Su significado metafísico proviene de su relación con el Creador. En el texto, las creaturas se vuelven canal «por» el que el hermano Francisco profiere la alabanza de su Señor.

Buenaventura de Bagnoregio explica la relación de Dios con las creaturas por medio de la analogía y la simbología. Por la primera, es posible descubrir en las creaturas las huellas de Dios, como sombra, vestigio o imagen. Por la segunda, algunos símbolos tradicionales son utilizados con explícita intención anagógica, para dirigir los ojos del alma a Dios.

El «Cantico» puede ser interpretado a la luz de la analogía y la simbología bonaventurianas. Por medio de ellas, las creaturas deben ser consideradas vestigios y símbolos del Creador, porque constituye su representación distante y distinta; al tiempo que lo señalan como su causa eficiente, ejemplar y final; y porque, conducen a la inteligencia humana a la consideración de su potencia, de su bondad y de su sabiduría.

El significado creatural del cosmos, percibido por los ojos del contemplativo Francisco de Asís, sienta las bases para una «metafísica» de la significación. En ella se recuerda que los elementos del cosmos son creaturas y hermanas, cuyo significado remite al Creador.

La experiencia espiritual de Francisco de Asís, y de su exégeta Buenaventura, resultan imprescindibles en nuestros días para la construcción de una «ecología integral» (papa Francisco, 2015: parágrafo 11). Gracias a ella se podría recuperar la mirada contemplativa del poverello, que permitió llamar hermanas a las creaturas. 


\section{REFERENCIAS BIBLIOGRÁFICAS}

Bauckham, R. (2011). Living with Other Creatures: Green Exegesis and Theology. Waco: Baylor University Press.

Berti, E. (1985). Il concetto di analogia in S. Bonaventura. Doctor Seraphicus, 32(1985), 11-21.

Beschin, G. (2000). La creatura simbolo del creatore in san Bonaventura alla luce della fede e la ragione. Doctor Seraphicus, 47(2000), 4364.

Bizziccari, A. (1972). Il Cantico delle creature o di Frate Sole. Questioni e note critiche. Italica, 49(2), 229243.

Bougerol, J. (1973). Dossier pour l'étude des rapports entre saint Bonaventure et Aristote. Archives d'Histoire Doctrinale et Littéraire du Moyen Âge, 40(1973), 135-222.

Bougerol, J. (1983). Francesco, guida alla perfezione evangelica, secondo la «Legenda Major» di Bonaventura. Doctor Seraphicus, 30(1983), 11-27.

Bougerol J.-G. (1988). Introduzione a san Bonaventura. Vicenza: L.I.E.F.

Brams, J. (2003). La riscoperta di Aristotele in Occidente. Milano: ISTEM-Jaca Book.

Buenaventura de Bagnoregio. (18821902). "Itineratium mentis in
Deum", t. V. p. 295-313. En Opera omnia. Florencia: Claras Aquas.

Buenaventura de Bagnoregio. (s/f). Itinerario del alma a Dios. Recuperado de http://www.dfists.ua.es/ gil/ itinerarium-mentis-in-deum-esp. pdf

Cilento, V. (1966). Simbolismo e analogia in San Bonaventura. Doctor Seraphicus, 13(1966), 49-81.

Congar, Y. (1961). Aspects ecclésiologiques de la querelle entre mendiants et séculiers dans la seconde moitié du XIIle siècle et le début du XVle. Archives d'Histoire Doctrinale et Littéraire du Moyen Âge, 36(1961), 35-151.

Cousins, E. (1978). Bonaventure and the coincidence of opposites, Chicago: Franciscan Herald Press.

Chavero, F. (1990). Per una teologia e antropologia dell'immagine in san Bonaventura. Doctor Seraphicus, 37(1990), 5-35.

Chenu, M.-D. (1992). La Teologia nel XII secolo. Milano: Jaca Book.

Damiata, M. (2004). L'ultimo Bonaventura. Studi francescani, 101(2004), 5-143.

Directorio Franciscano. (s/f). San Francisco y el lobo de Gubbio. Recuperado de http://www.franciscanos. org/sfa/gubbio.html 
Ferrater Mora, J. (1981). Diccionario de FiIosofía, 1. Madrid: Alianza Editorial. Forcellini, AE. (1949). Lexicon totius latinitatis. Patavii: typis seminarii.

Francesco d'Assisi. (1997). Cantico di Frate Sole. Recuperado de http://www. letteraturaitaliana.net/pdf/Volume $1 / \mathrm{t} 16 . \mathrm{pdf}$

Flors, J. (editor). (1969). Historia de la espiritualidad I. Espiritualidad católica (primera parte). Barcelona.

Fuentes Biográficas Franciscanas. (s/f). San Buenaventura: Leyenda Mayor de san Francisco. Recuperado de http://www.franciscanos.org/ fuentes/Ima03.html

Gilson, E. (1965). The philosophy of St. Bonaventure. Paterson (N.J.): St. Anthony Guil Press.

Gilson, E. (1995). La Filosofia di San Bonaventura. Milano: Jaca Book.

Gregory, T. (1964). Filosofia e Teologia nella crisi del XIII secolo. Belfagor, 19(1964), 1-16.

Knowles, M. (1977). Nueva historia de la Iglesia. Tomo II. La Iglesia en la Edad Media. Madrid: Cristiandad.

Lázaro, M. (2008). Filosofía e Espiritualidad en el Itinerarium mentis in Deum de San Buenaventura. Revista Portuguesa de Filosofía, 64(1), 105-136.

Malaguti, M. (1996). Ermeneutica bíblica e testimonianza in s. Francesco e s. Bonaventura. Doctor Seraphicus,
43(1996), 85-93.

Martin, M. (2015). The Human-Nature Relationship: Challenges for Practical Theology and Christian Discipleship. Practical Theology, vol. 8 (3 y 4), 167-176, DOl: 0.1080/1756073X.2015.1109216. Recuperado de http://dx.doi.or/ 10.1080/1756073X.2015.1109216

Mauro, L. (1982). S. Bonaventura e l'averroismo latino: insegnamenti di una controversia. Doctor Seraphicus, 29(1982), 9-24.

Maranesi, P. (1995). Per un contributo alla "questione bonaventuriana". Wissenschaft und Weisheit, 58/2(1995), 287-314.

Matura, Th. (2010). Francis of Assisi Heritage and Heirs: Eight Centuries Later. Ashland: The Franciscan Institute Publications.

Paolazzi, C. (1992). Cantico di frate Sole. Genova: Marietti.

papa Francisco. (2015). Laudato si.' En Recuperado de http://w2.vatican. $\mathrm{va/content/francesco/es/ency-}$ clicals/documents/papa-francesco 20150524 enciclica-laudato-si.html

Raitt, J. (2002). Espiritualidad cristiana. Alta Edad Media y Reforma. Buenos Aires: Lumen.

Ratzinger, J. (2010). La teología de la Historia de san Buenaventura (2a. ed.). Madrid: Encuentro. 
Stabile, G. (1995). L'autunno del medioevo. En Malato, E. (Ed.), Storia della letteratura italiana I (pp. 725-772). Roma: Salerno Editrice.

Steenberghen, F. [van]. (1955). The philosophical movement in the thirteenth century. Belfast: Nelson.

Steenberghen, F. [van]. (1974). Introduction à Létude de la Philosophie
Médiévale, Louvain: Publication Universitaires.

Todisco, O. (1980). Dall'analogia al simbolo e dal simbolo all'analogia in San Bonaventura. Doctor Seraphicus, 27(1980), 5-19.

Verger, J. (1996). Istituzione e sapere nel XIII secolo. Milano: ISTEM - Jaca Book. 